The only severe general reactions in this series occurred in the first year of treatment when the depot pollen emulsion was in an early stage of its development and there may have been some free aqueous pollen solution present due to instability of the emulsion at that time.

All patients, however, who had severe local or general reactions were very happy to have further injections of the same material. Those who had previously had aqueous pollen injections were unanimously in favour of the depot pollen emulsion treatment because of the small number of injections required.

One cannot exactly equate pollen provocation tests with naturally occurring pollen exposure, but it would seem likely from our results that a patient who can tolerate 3,000 Noon units of aerosolized pollen breathed in five minutes is not likely to get pollen asthma under normal conditions of natural exposure. This degree of protection is produced in some, but not all, patients by depot pollen injections. The degree of objective improvement in the individual patient increases after each year's treatment in most cases.

\section{Conclusions}

Depot pollen injections can produce a high degree of bronchial tolerance to inhaled pollen solution in over $70 \%$ of patients.

This tolerance is partially lost before the next winter in about $80 \%$ of "protected" patients.

Further courses of treatment will usually boost the tolerance to even higher levels.

Very large final doses of depot pollen do not necessarily produce more improvement than the standard doses.

Clinical improvement runs parallel to the increases in bronchial tolerance in most patients.

\section{Summary}

Thirty-one patients with severe grass-pollen asthma were subjected to quantitative bronchial tolerance tests before and after treatment with depot pollen injections.

Very marked increases in bronchial tolerance occurred in $75 \%$ of patients after one year's treatment and in $80 \%$ after two years' treatment. A third year's treatment with very high dosage of depot pollen emulsion did not produce a much higher success rate.

The symptomatic response was roughly parallel to the results of the objective tests and the same proportion of patients were improved.

Failure to respond to treatment may be associated with sensitivity to other allergens than pollen, a tendency to winter bronchitis, and previous failure to respond to aqueous pollen injections.

This work was supported by a grant from the Asthma Research Council. We are grateful to Dr. F. H. Milner, of Beecham Research Laboratories, for supplying the depot pollen injections.

\section{REFERENCES}

Arbesman, C. E., and Reisman, R. E (1964), 7. Allergy, 35, 12 Armitage, P., Herxheimer, H., and Rosa, L. (1952). Brit. F. Pharmacol.

Brown, E25. A. (1957). Ann. Allergy, 15, 499.

Brown, E. A. (1957). Ann. (1958a). Ibid., 16, 281. (1958b). Ibid., 17, 1610 (1961). Ibid., 19, 637. (1962). Ibid., 20, 397.

Feinberg, A. R., Feinberg, S. M., and Fisherman, E. W. (1960). 9. Allergy, 31, 433.

Frankland $\mathbf{W}$ Eipans, $R$ G. Macaulay, D. B., and Edwards, J. W (1964). Practitioner, 193, 71

Herxheimer, H. (1951). Lancet, 1, 1337.

Herxheimer, H. (1951). Lancet, 1, 1337. Sci., 214, 559.

Loveless, M. H. (1947). Amer. 7 med.

McAllen, M. K. (1961), Thorax, 16, 30. 148.

\title{
Injuries Due to Accidental Injection of Paint from High-pressure Paint Guns
}

\author{
R. MORLEY,* M.B., CH.B., D.I.H.
}

Brit. med. 7., 1957, 1, 25-26

Injury due to the injection of paint has not been described in this country, though Nahigian (1966) reported two cases in the U.S.A. Similar types of injury with grease or diesel oil were described by Rees (1937), Brooke and Rooke (1939), and F. H. Smith (1939). More recently, M. G. H. Smith (1964) described grease-gun injuries from high-pressure greasing in garages. $\mathrm{He}$ reported five cases and made a survey of the 31 cases recorded in the English literature, 22 due to grease, 5 to diesel oil, and the rest to a variety of other oils. He concluded: "There is a lack of awareness among doctors of the serious nature of grease-gun injuries and a lack of awareness of the dangers of high-pressure lubrication equipment among garage workers. Grease-gun injuries should be treated as emergencies; a wide exploration of the part is essential to remove as much grease as possible."

There is no difference between the injuries due to paint and those due to grease except the different material, and in the body these appear to be equally damaging. As will be seen from the cases described below, paint shows up well on $x$-ray films whereas grease does not; therefore the surgeon can see where the paint is and how successful he has been in its removal. Early exploration of the wound cannot be made unless the work-

* H.M. Medical Inspector of Factories, Northern Division, Newcastle upon Tyne. men realize the seriousness of the apparent minor injury; the first-aid attendant and the surgeon know that surgical intervention is essential to the removal of the paint.

\section{Painting Techniques}

Paint spraying is done by the following three methods.

1. Compressed air is mixed with paint and forced through the nozzle of a gun. Air pressures are between 60 and $200 \mathrm{lb} . / \mathrm{sq}$. in. (4.2 and $14 \mathrm{~kg} . / \mathrm{sq}$. cm.).

2. Paint is placed in a pressure receiver and air at 60 to 200 lb./sq. in. ( 4.2 to $14 \mathrm{~kg}$./sq. cm.) is introduced at the top of the receiver and liquid paint expelled through a pipe-line to a gun from the bottom of the container. No perforating injuries of the skin have been reported from these two methods.

3. Compressed air is used at pressures above $40 \mathrm{lb} . / \mathrm{sq}$. in. $(2.8 \mathrm{~kg} . / \mathrm{sq}$. $\mathrm{cm}$.) to drive a ram pump which sucks up the paint and forcibly expels it. In the pumps the ratio between the air pressure and the paint pressure has not exceeded 1:50, but with an air pressure of $60 \mathrm{lb} . / \mathrm{sq}$. in. $(4.2 \mathrm{~kg} . / \mathrm{sq} . \mathrm{cm}$.) a hydrostatic paint pressure of $3,000 \mathrm{lb} . / \mathrm{sq}$. in. $(211 \mathrm{~kg} . / \mathrm{sq}$. $\mathrm{cm}$.) is produced. The mechanism is identical with that of the highpressure grease guns ; these can be obtained working at $150 \mathrm{lb} . /$ sq. in. $(10.5 \mathrm{~kg} . / \mathrm{sq} . \mathrm{cm}$.) and a ratio of $1: 70$, giving a hydro- 
static grease pressure of $10,500 \mathrm{lb} . / \mathrm{sq}$. in. (738 kg./sq. cm.). Such high pressures have not yet been encountered in highpressure spray-painting. Technically it is claimed that this method gives a better coverage of the metal with less overspray. At the time of writing this equipment has been found only in shipyards and has apparently been coming into general usage here in the past 18 months.

\section{Case Reports}

Case 1.-In December 1965 a 38-year-old painter was spraypainting the outside shell of a ship when the nozzle blocked. He switched off the pump and unscrewed the nozzle, and a jet of paint entered his left thumb. This caused a small hole in the pad of the thumb with no swelling. The first-aid attendant advised him to go to the hospital, where a simple dressing was applied. Twenty-four hours later the thumb was much worse and a 2 -in. $(5 \mathrm{~cm}$.) incision was made extending from the nail to the interphalangeal joint. and swollen, and two weeks after that amputation was performed through the proximal interphalangeal joint.

\section{Discussion}

In these three cases the ambulance room attendant gave correct advice. It must be emphasized that different shipyards and different hospitals were concerned in these cases. The general practitioner was apparently not involved in any of them, as the injured man went direct from the works ambulance-room to the hospital. Unfortunately, in every case the seriousness of the injury was not appreciated, though an $x$-ray examination would have shown the need for surgical debridement. With such a method of painting it appears likely that for some reason or other the spray may, on occasion, penetrate the skin.

Morley (1966) found that penetration of the skin of amputated limbs did not occur with grease pressure of less than $7,000 \mathrm{lb} . / \mathrm{sq}$. in. (492 kg./sq. cm.) but could occur at 9 in. (23

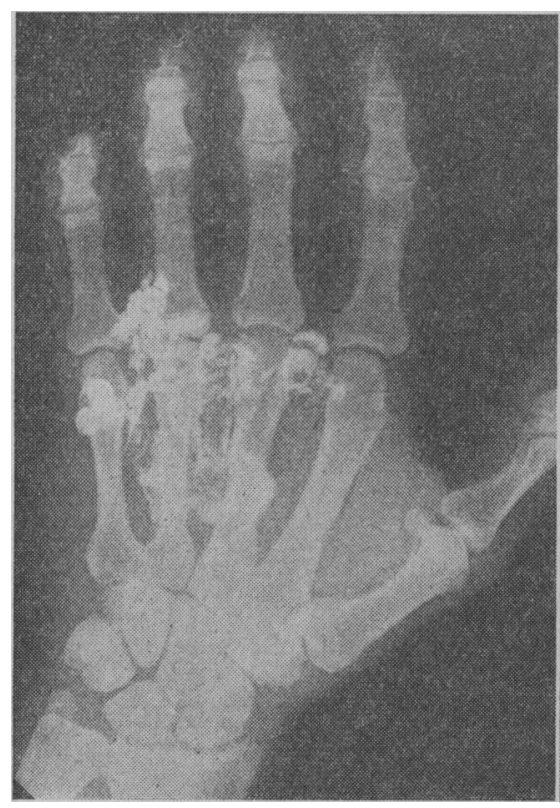

Fig. 1.-X-ray picture of Case 2.

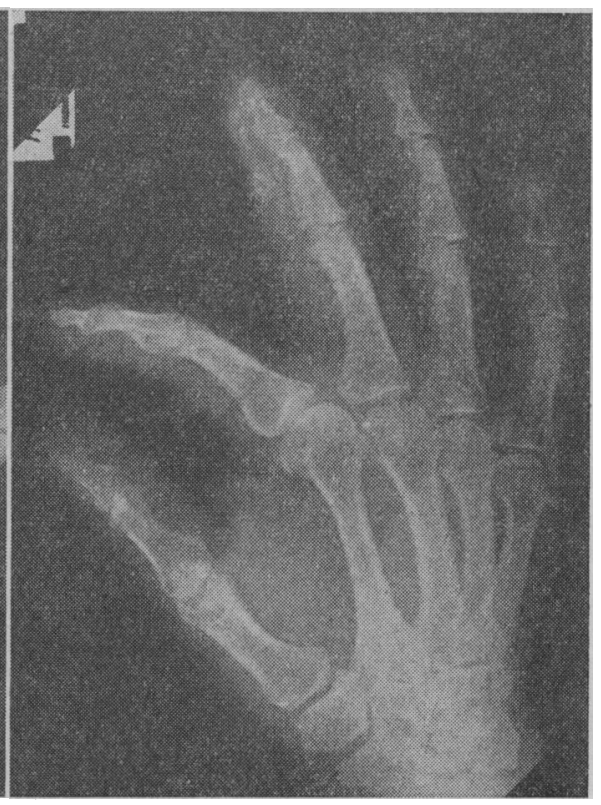

FIG. 2.-X-ray picture of Case 3.

cm.) distance with a pressure of $10,500 \mathrm{lb} . / \mathrm{sq}$. in. (738 kg./sq. $\mathrm{cm}$.). In the present cases it appears to have occurred at a pressure of between 2,000 and 3,000 lb./sq. in. (141 and 211 $\mathrm{kg}$./sq. cm.). The difference is possibly accounted for by the different viscosities of grease and paint.

\section{Summary}

The dangers of high-pressure paint-spraying equipment are described, and illustrated by three recent cases. The importance of extensive incision and evacuation of the paint at the earliest possible moment is emphasized. The usefulness of $x$-ray pictures in the case of these paint injuries is emphasized, especially as the idea may be prevalent that they are of little use, which is in fact true in the case of grease-gun injuries.

I wish to thank Dr. T. A. Lloyd Davies, H.M. Senior Medical Inspector of Factories, for encouragement and permission to publish this paper; and also Mr. E. Dayan, casualty surgeon, Ingham Infirmary, South Shields, and Mr. J. B. B. Milne, surgical registrar, the Royal Infirmary, Sunderland, for details concerning their respective cases and for the $x$-ray films.

\section{REFERENCES}

Brooke, R., and Rooke, C. J. (1939). Brit. med. F., 2, 1186.

Morley, R. (1966). Brit. F. industr. Med. In press.

Nahigian, S. H. (1966). F. Amer. med. Ass., 195, 688.

Rees, C. E. (1937). Ibid., 109, 866.

Smith, F. H. (1939). Ibid. $112,907$.

Smith, M. G. H. (1964). Brit. med. F., 2, 918. the finger became so painful that at 4 a.m. he went to hospital. Later that morning a radiograph was taken (Fig. 2) and he was operated upon immediately. Four weeks later the finger was stiff 